\title{
STUDI PENGARUH PENAMBAHAN ABU SEKAM PADI TERHADAP KUAT TEKAN BETON
}

\author{
Samsudin $^{1}$, Sugeng Dwi Hartantyo ${ }^{2}$ \\ ${ }^{1}$ Program Studi Teknik Sipil Fakultas Teknik Universitas Islam Lamongan \\ ${ }^{2}$ Dosen Program Studi Teknik Sipil Fakultas Teknik Universitas Islam Lamongan \\ E-mail: samsudinarch@gmail.com, sugengdwi@gmail.com
}

\begin{abstract}
ABSTRAK
Sekam padi merupakan limbah dari hasil penggilingan padi mempunyai kandungan silika yang dominan yaitu sebesar $93 \%$ dan hampir sama kandungan silika yang terdapat pada microsilica buatan pabrik. Dengan sifatnya tersebut apabila dicampurkan ke dalam campuran beton akan memperbaiki karakteristik beton. Dalam penelitian ini abu sekam padi ditambahkan ke dalam adukan beton fc' K-175 $\mathrm{Kg} / \mathrm{cm} 2$ dengan variasi penambahan abu sekam $0 \%, 8 \%, 10 \%$, dan $12 \%$, persentasi berat abu sekam ini diambil berdasarkan berat semen. Penelitian ini bertujuan untuk mengetahui nilai kuat tekan beton yang dicapai dari campuran abu sekam padi dalam beton $\mathrm{K}-175 \mathrm{Kg} / \mathrm{cm} 2$. Rancangan adukan beton menggunakan metode ASTM. Benda uji yang dibuat untuk masing-masing penambahan persentase abu sekam adalah sebanyak 3 sampel, dengan ukuran cetakan silinder berdiameter $15 \mathrm{~cm}$ dengan tinggi 30 $\mathrm{cm}$. Berdasarkan tabel 4.22 di peroleh hasil bahwa terjadi penurunan kekuatan pada setiap penambahan kadar abu sekam padi. Di ketahui kuat tekan beton normal umur 28 hari yaitu $226,47 \mathrm{~kg} / \mathrm{m}^{2}$ dan kuat tekan terendah terdapat pada penambahan abu sekam padi $12 \%$ umur 28 hari yaitu $129,41 \mathrm{~kg} / \mathrm{m}^{2}$.
\end{abstract}

Kata kunci : Sekam Padi, Kuat Tekan, Metode ASTM

\begin{abstract}
Rice husk is the waste from the rice mill has a dominant silica content that is equal to $93 \%$ and almost the same content of silica contained in the microsilica manufactured. By its nature when mixed into the concrete mix will improve the characteristics of concrete. In this research, rice husk ash was added to the concrete mixture of $F_{c}{ }^{\prime} \mathrm{K}-175 \mathrm{Kg} / \mathrm{cm} 2$ with a variation of $0 \%, 8 \%, 10 \%$, and $12 \%$ husk ash ash taken based on the weight of cement. This research aims to determine the value of concrete compressive strength achieved from rice husk ash mixture in $\mathrm{K}-175 \mathrm{Kg} / \mathrm{cm} 2$ concrete. Concrete mortar design using ASTM method. Test specimens were made for each addition of the percentage of husk ash is as much as 3 samples, with cylinder mold size $15 \mathrm{~cm}$ diameter with height $30 \mathrm{~cm}$. Based on Table 4:22 in the results obtained that there is a decrease in strength on each addition of ash rice husk level. It is known that the normal compressive strength of 28 days old concrete is $226,47 \mathrm{~kg} / \mathrm{m} 2$ and the lowest compressive strength is in the addition of rice husk ash $12 \%$ age 28 day that is $129,41 \mathrm{~kg} / \mathrm{m} 2$.
\end{abstract}

Keywords : Rice Husk, Compressive Strength, ASTM Method. 


\section{PENDAHULUAN}

Beton adalah suatu material yang terdiri dari campuran semen portland, air, agregat kasar (kerikil) dan agregat halus (pasir) serta bahan tambahan bila diperlukan. Campuran dari bahan-bahan tersebut harus ditetapkan sedemikian rupa sehingga menghasilkan beton segar yang mudah dikerjakan.

Beton merupakan salah satu bahan konstuksi yang seringkali dipergunakan dalam struktur bangunan modern. Tingkat kebutuhan penggunaan beton di masyarakat sebagai struktur bangunan sangat tinggi. Karena beton dinilai lebih praktis dan lebih ekonomis dibanding dengan material konstruksi yang lain. Kadar semen dalam beton berpengaruh terhadap kuat tekan beton.

Semen merupakan salah satu bahan utama dalam pembuatan beton. Bahan mentah yang digunakan dalam pembuatan semen adalah batu kapur, pasir silika, tanah liat dan pasir besi. Total kebutuhan bahan mentah yang digunakan untuk memproduksi semen yaitu. Batu kapur digunakan sebanyak $\pm 81 \%$. Pasir silika digunakan sebanyak $\pm 9 \%$ Tanah liat digunakan sebanyak $\pm 9 \%$. Pasir besi digunakan sebanyak $\pm 1 \%$, pada penggilingan akhir digunakan gipsum sebanyak 35\%.(https://arpumiko.Wordpress.com

/2008/10/11/bahan-baku-pembuatan-semen/).

Semen merupakan material terbuat dari bahan bahan yang tergolong dari sumber daya alam yang tidak bisa diperbarui, sehingga persediaan bahan baku pembuatan semen di alam semakin sedikit. Penambangan bahan baku semen yang dilakukan secara terus menerus berdampak pada kerusakan alam.Hal tersebut mendorong ditemukannya material material alternatif sebagai bahan tambahan pada pembuatan beton.

Indonesia merupakan negara agraris penghasil beras di Asia Tenggara. Berdasarkan hal tersebut banyak sekali limbah padi yang dihasilkan, yaitu berupa sekam dan jerami padi. Sekam padi merupakan limbah pertanian melimpah yang jarang dimanfaatkan masyarakat sebagai bahan tambahan pembuatan beton. Masyarakat biasanya memanfaatkan sekam padi untuk bahan bakar memasak ataupun perapian untuk ternak. sekam padi memiliki kandungan mineral yang sama dengan kandungan mineral pada semen. Kandungan silika dari ekstraksi abu sekam padi adalah sebesar $\quad 82,26 \quad \%$. ilmiah.um.ac.id/index.php/kimia/

article/view/20883).

Berdasarkan perihal tersebut, tujuan peneliti melakukan penelitian tentang "Studi Pengaruh Penambahan Abu Sekam Padi Terhadap Kuat Tekan Beton" adalah untuk mengetahui proses penambahan abu sekam padi pada campuran beton, mengetahui dan menganalisa seberapa besar pengaruh penambahan abu sekam terhadap kuat tekan beton serta memanfaatkan dan mendaur ulang sekam padi secara optimal.

\section{METODE PENELITIAN}

Metode yang digunakan dalam penelitian adalah uji eksperimental di laboratorium. Adapun material yang akan diuji adalah sebagai berikut :

a. Sekam

Sekam padi yang digunakan adalah sekam dari padi pasca panen dalam keadaan kering. Metode pembuatan abu sekam dilakukan dengan cara membakar sekam tersebut hingga menjadi abu.

b. Benda uji

Benda uji berbentuk silinder padat tidak berongga dan berukuran diameter $15 \mathrm{~cm}$ dan tinggi $30 \mathrm{~cm}$. pengujian kuat tekan dlakukan setelah umur beton mencapai 7 hari yang kemudian dikorelasikan ke umur 28 hari

Tabel 1. Prosentase Komposisi Bahan pada Varisasi Campuran Beton

\begin{tabular}{llllll}
\hline \multicolumn{5}{l}{ Komposisi Bahan } \\
\hline Kode & Semen & $\begin{array}{l}\text { Abu } \\
\text { Sekam }\end{array}$ & $\begin{array}{l}\text { Agregat } \\
\text { Halus }\end{array}$ & $\begin{array}{l}\text { Agregat } \\
\text { Kasar }\end{array}$ & Air \\
\hline Normal & $100 \%$ & $0 \%$ & $100 \%$ & $100 \%$ & $100 \%$ \\
\hline B 8\% & $92 \%$ & $8 \%$ & $100 \%$ & $100 \%$ & $100 \%$ \\
\hline B 10\% & $90 \%$ & $10 \%$ & $100 \%$ & $100 \%$ & $100 \%$ \\
\hline B 12\% & $88 \%$ & $12 \%$ & $100 \%$ & $100 \%$ & $100 \%$ \\
\hline Sumber : Hasil Penelitian, 2017
\end{tabular}

\section{Teknik Pengumpulan Data}

Langkah - langkah yang diperlukan dalam pengumpulan data untuk mendukung data data yang disusun dalam penelitian ini adalah sebagai berikut :

\section{Eksperimen}

Eksperimen adalah suatu kegiatan bersifat ilmiah yang bertujuan memperoleh data berdasarkan dari hasil penelitian tersebut. Dari langkah tersebut akan diperoleh data primer.

\section{Studi literatur}

Studi literatur adalah mencari data-data maupun informasi yang berkaitan dengan penelitian melelui membaca buku maupun di internet 
sebagai acuan dalam penelitian. Dari langkah tersebut diperoleh data sekunder.

\section{Pelaksanaan Penelitian}

\section{Lokasi penelitian}

Lokasi penelitian maupun pengujian dilakukan di Laboratorium Teknik Sipil UNISLA

\section{Bahan}

Bahan bahan yang digunakan dalam pebuatan benda uji adalah
a. Semen Portland
b. Agregat kasar (kerikil)
c. Agregat halus (pasir)
d. Abu sekam padi
e. Air tawar

\section{Peralatan}

Peralatan yang dibutuhkan dalam penelitian ini adalah :
a. Alat pencampur bahan :
- Concrete mixer
- Sekop /sendok semen

b. Cetakan silinder beton

c. Mesin tekan hidrolis untuk menguji kuat tekan beton

\section{Penyelidikan Bahan dan Beton}

a. Penyelidikan bahan semen

- Percobaan Konsistensi Normal Semen Portland (ASTM C 187-86)

- Percobaan Waktu Mengikat dan Mengeras Semen (ASTM 191-92)

- Percobaan Menentukan Berat Jenis Semen (ASTM C 188 - 89)

b. Penyelidikan bahan pasir

- Pengujian ayakan pasir (ASTM C 33 - 78)

- Pengujian Kadar Air Agregat (ASTM C 556 89)

- Percobaan Berat Jenis Pasir ( ASTM C 128 93 )

- Percobaan Air Resapan Pasir (ASTM C 128 93)

- Percobaan Bobot Isi dan Rongga Udara Dalam Pasir (ASTM C 29M - 91)

c. Penyelidikan bahan kerikil

- Hasil pengujian ayakan kerikil (ASTM C 33 93)

- Hasil Pengujian Kelembaban Kerikil (ASTM C $556-89)$

- Pengujian Berat Jenis Kerikil (ASTM C 128-78)

- Pengujian Kadar Air Resapan Kerikil(ASTM C $127-88-93)$

- Pengujian Berat Volume Batu Pecah (ASTM C $29-91)$

\section{HASIL DAN PEMBAHASAN}

Hasil dari penelitian yang dilakukan di Laboratorium Teknik Sipil Fakultas Teknik Universitas Islam Lamongan, merupakan suatu pencarian data yang mengacu pada perumusan masalah, yaitu untuk mengetahui pengaruh penambahan abu sekam padi sebagai bahan campuran beton.

Tabel 2. Kesesuaian Hasil Penelitian Analisa Semen Dengan Kajian Pustaka

\begin{tabular}{|c|c|c|c|c|}
\hline No & $\begin{array}{l}\text { Uraian } \\
\text { kegiatan }\end{array}$ & $\begin{array}{l}\text { Kajian } \\
\text { pustaka/landas } \\
\text { an teori }\end{array}$ & $\begin{array}{l}\text { Hasil } \\
\text { penelitian }\end{array}$ & Ket \\
\hline 1 & $\begin{array}{l}\text { Konsistensi } \\
\text { Normal } \\
\text { Semen } \\
\text { Portland }\end{array}$ & $\begin{array}{l}\text { (ASTM C 187- } \\
86) \text { konsistensi } \\
\text { semen berkisar } \\
\text { antara } 26 \% \text { - } \\
29 \% \text {. }\end{array}$ & $\begin{array}{l}\text { kondisi } \\
\text { kebasahan } \\
\text { pasta yang } \\
\text { standart } \\
\text { ialah } 28 \%\end{array}$ & $\begin{array}{l}\text { Memen } \\
\text { uhi }\end{array}$ \\
\hline 2 & $\begin{array}{l}\text { Pengujia } \\
\mathrm{n} \quad \text { Berat } \\
\text { Jenis } \\
\text { Semen }\end{array}$ & $\begin{array}{l}\text { (ASTM C } 188- \\
\text { 89)Berat jenis } \\
\text { semen Portland } \\
\text { mempunyai } \\
\text { kisaran 3,0-3,2 }\end{array}$ & $\begin{array}{l}\text { Dari } \\
\text { pengujian } \\
\text { berat jenis } \\
\text { semen } \\
\text { adalah } \\
2,329 .\end{array}$ & $\begin{array}{l}\text { Tidak } \\
\text { Memen } \\
\text { uhi }\end{array}$ \\
\hline
\end{tabular}

Sumber : Hasil Penelitian, 2017

Dari pengujian bahan semen yang dilakukan hanya pengujian konsistensi normal semen Portland yang memenuhi standart ASTM

Tabel 3. Kesesuaian Hasil Penelitian Agregat Halus dengan Kajian Pustaka

\begin{tabular}{|c|c|c|c|c|}
\hline No & $\begin{array}{l}\text { Uraian } \\
\text { kegiatan }\end{array}$ & $\begin{array}{l}\text { Kajian } \\
\text { pustaka/land } \\
\text { asan teori }\end{array}$ & $\begin{array}{l}\text { Hasil } \\
\text { penelitian }\end{array}$ & Ket \\
\hline 1 & $\begin{array}{l}\text { Pengujia } \\
\text { n ayakan } \\
\text { pasir }\end{array}$ & $\begin{array}{l}\text { (ASTM C } 33 \\
-\quad 78) \text { nilai } \\
\text { yang } \\
\text { disyaratkan } \\
\text { antara } 2,2-3,1\end{array}$ & $\begin{array}{l}\text { Hasil ayakan } \\
\text { pasir dari } \\
\text { pengujian } \\
\text { sebesar } \\
3,705 \% \text {. }\end{array}$ & $\begin{array}{l}\text { tidak } \\
\text { memen } \\
\text { uhi } \\
\text { syarat }\end{array}$ \\
\hline 2 & $\begin{array}{l}\text { Pengujia } \\
\mathrm{n} \\
\text { Kelemba } \\
\text { ban pasir }\end{array}$ & $\begin{array}{l}(\text { ASTM C 566 } \\
-\quad 89) \\
\text { kelembaban } \\
\text { pasir sebesar } \\
<0,1 \%\end{array}$ & $\begin{array}{l}\text { Kelembaban } \\
\text { pasir rata-rata } \\
\text { didapat nilai } \\
5,605 \%\end{array}$ & $\begin{array}{l}\text { tidak } \\
\text { memen } \\
\text { uhi } \\
\text { syarat }\end{array}$ \\
\hline 3 & $\begin{array}{l}\text { Pengujia } \\
\text { n Berat } \\
\text { Jenis } \\
\text { pasir }\end{array}$ & $\begin{array}{l}\text { (ASTM C } 128 \\
-78) \text { berat } \\
\text { jenis } \quad \text { pasir } \\
\text { antara } 2,4 \quad- \\
2,7 \mathrm{gr} / \mathrm{dm}^{3} .\end{array}$ & $\begin{array}{l}\text { Berat jenis pasir } \\
\text { rata-rata dari } \\
\text { hasil pengujian } \\
\text { sebesar } \\
2,62 \mathrm{gr} / \mathrm{dm}^{3}\end{array}$ & $\begin{array}{l}\text { memen } \\
\text { uhi } \\
\text { syarat }\end{array}$ \\
\hline 4 & $\begin{array}{l}\text { Pengujia } \\
\mathrm{n} \quad \text { Air } \\
\text { Resapan } \\
\text { Agregat } \\
\text { Halus }\end{array}$ & $\begin{array}{l}\text { (ASTM C } 128 \\
-93) \text { nilai } \\
\text { yang } \\
\text { disyaratkan } \\
\text { antara } 1-4 \%,\end{array}$ & $\begin{array}{l}\text { Hasil uji kadar } \\
\text { air resapan } \\
\text { didapat rata-rata } \\
4,07 \% \text {, }\end{array}$ & $\begin{array}{l}\text { memen } \\
\text { uhi } \\
\text { syarat }\end{array}$ \\
\hline 5 & $\begin{array}{l}\text { Pengujia } \\
\mathrm{n} \quad \text { Berat } \\
\text { Volume } \\
\text { Agregat } \\
\text { Halus }\end{array}$ & $\begin{array}{l}\text { (ASTM C } 29 \\
\text { M - 91) nilai } \\
\text { yang } \\
\text { disyaratkan } \\
\text { antara } 1,25- \\
1,59\end{array}$ & $\begin{array}{lr}\text { hasil uji berat isi } \\
\text { rata - rata } \\
\text { sebesar } \\
\text { gr/lt }\end{array}$ & $\begin{array}{l}\text { Memen } \\
\text { uhi } \\
\text { syarat }\end{array}$ \\
\hline
\end{tabular}


J u r n a l T e k n i k A

V o l 9 N o 2 S e p t e m b e r $2017,929-935$

Berdasarkan tabel di atas hasil pengujian ayakan pasir dan kelembaban pasir tidak memenuhi persyaratan

Tabel 4. Kesesuaian Hasil Penelitian Analisa Agregat kasar dengan Kajian Pustaka

\begin{tabular}{|c|c|c|c|c|}
\hline No & $\begin{array}{l}\text { Uraian } \\
\text { kegiatan }\end{array}$ & $\begin{array}{l}\text { Kajian } \\
\text { pustaka/landasan } \\
\text { teori }\end{array}$ & $\begin{array}{l}\text { Hasil } \\
\text { penelitian }\end{array}$ & Ket \\
\hline 1 & $\begin{array}{l}\text { pengujiann } \\
\text { ayakan } \\
\text { kerikil }\end{array}$ & $\begin{array}{l}\text { (ASTM C } 33-93) \\
\text { batas yang } \\
\text { diijinkan, yaitu } 6- \\
7 \%\end{array}$ & $\begin{array}{l}\text { Hasil } \\
\text { pengujian } \\
\text { didapat } \\
\text { nilai FM = } \\
4,458 \% .\end{array}$ & $\begin{array}{l}\text { tidak } \\
\text { memen } \\
\text { uhi } \\
\text { syarat. }\end{array}$ \\
\hline 2 & $\begin{array}{l}\text { Pengujian } \\
\text { Kelembaban } \\
\text { Kerikil }\end{array}$ & $\begin{array}{l}\text { (ASTM C } 556- \\
89) \text { nilai yang } \\
\text { disyaratkan antara } \\
0-3 \% \text {. }\end{array}$ & $\begin{array}{l}\text { Rata-rata } \\
\text { kelembaban } \\
\text { kerikil } \\
1,265 \% .\end{array}$ & $\begin{array}{l}\text { memen } \\
\text { uhi } \\
\text { persyar } \\
\text { atan }\end{array}$ \\
\hline 3 & $\begin{array}{l}\text { Pengujian } \\
\text { Berat Jenis } \\
\text { Kerikil }\end{array}$ & $\begin{array}{l}\text { (ASTM C 128-78) } \\
\text { berat jenis kerikil } \\
\text { yang disyaratkan } \\
\text { antara } 2,2-2,7 \\
\text { gr/dm } \mathrm{dm}^{3}\end{array}$ & $\begin{array}{l}\text { Berat jenis } \\
\text { kerikil rata- } \\
\text { rata } 2,37 \\
\mathrm{gr} / \mathrm{dm}^{3} \text {. }\end{array}$ & $\begin{array}{l}\text { memen } \\
\text { uhi } \\
\text { syarat }\end{array}$ \\
\hline 4 & $\begin{array}{l}\text { Pengujian } \\
\text { Kadar Ail } \\
\text { Resapan } \\
\text { Kerikil }\end{array}$ & $\begin{array}{l}\text { (ASTM C } 127- \\
88-93) \text { batas } \\
\text { yang } \\
\text { diperbolehkan } \\
\text { antara } 1 \%-4 \% \text {. }\end{array}$ & $\begin{array}{l}\text { rata-rata } \\
\text { dari hasil } \\
\text { pengujian } \\
1,88 \% .\end{array}$ & $\begin{array}{l}\text { memen } \\
\text { uhi } \\
\text { syarat }\end{array}$ \\
\hline 5 & $\begin{array}{l}\text { Pengujian } \\
\text { Berat } \\
\text { Volume Batı } \\
\text { Pecah }\end{array}$ & $\begin{array}{l}\text { (ASTM C 29-91) } \\
\text { nilai yang disyarat } \\
\text { antara } 1,4 \text { sampai } \\
1,7 \mathrm{~kg} / \mathrm{lt} \text {. }\end{array}$ & $\begin{array}{l}\text { Rata-rata } \\
\text { berat } \\
\text { volume } \\
\text { pasir } 1,432 \\
\text { kg/lt. }\end{array}$ & $\begin{array}{l}\text { memen } \\
\text { uhi } \\
\text { syarat. }\end{array}$ \\
\hline
\end{tabular}

Sumber : Hasil Penelitian, 2017
Dari pengujian agregat kasar yang dilakukan hanya pengujian ayakan kerikil yang tidak memenuhi syarat ASTM

Tabel 5. Kesesuaian Hasil Penelitian Analisa Abu Sekam Padi Dengan Kajian Pustaka

\begin{tabular}{|c|c|c|c|c|}
\hline No & $\begin{array}{l}\text { Uraian } \\
\text { kegiatan }\end{array}$ & $\begin{array}{l}\text { Kajian } \\
\text { pustaka/land } \\
\text { asan teori }\end{array}$ & $\begin{array}{l}\text { Hasil } \\
\text { penelitian }\end{array}$ & Ket \\
\hline 1 & $\begin{array}{l}\text { Konsiste } \\
\text { nsi } \\
\text { Normal } \\
\text { Semen } \\
\text { Portland } \\
\text { dan abu }\end{array}$ & $\begin{array}{l}\text { ASTM C } \\
\text { 187-86) } \\
\text { konsistensi } \\
\text { semen } \\
\text { berkisar } \\
\text { antara 26\% - } \\
29 \% \text {. }\end{array}$ & 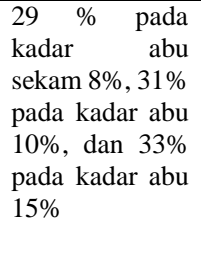 & $\begin{array}{l}\text { Hanya } \\
\text { kadar } \\
\text { abu } \\
\text { sekam } \\
5 \% \\
\text { yang } \\
\text { memen } \\
\text { uhi }\end{array}$ \\
\hline 2 & $\begin{array}{l}\text { Pengujian } \\
\text { Berat Jenis } \\
\text { abu sekan } \\
\text { padi }\end{array}$ & $\begin{array}{l}\text { (ASTM } \mathrm{C} \\
188-89) \\
\text { Berat jenis } \\
\text { semen } \\
\text { Portland } \\
\text { mempunyai } \\
\text { kisaran } 3,0- \\
3,2\end{array}$ & $\begin{array}{l}\text { rata-rata berat } \\
\text { jenis abu sekam } \\
5 \%=0,912 \text { gr. } \\
\text { rata-rata berat } \\
\text { jenis abu sekam } \\
10 \%=0,7248 \\
\text { gr. rata-rata } \\
\text { berat jenis abu } \\
\text { sekam } 15 \%= \\
0,5885 \mathrm{gr}\end{array}$ & $\begin{array}{l}\text { Tidak } \\
\text { Memen } \\
\text { uhi }\end{array}$ \\
\hline
\end{tabular}

Sumber : Hasil Penelitian, 2017

Dari pengujian analisa abu sekam yang dilakukan hanya pengujian konsistensi normal dan abu sekam denagan kadar $8 \%$ yang memenuhi syarat ASTM

Tabel 6. Pengujian Kuat Tekan Beton Silinder

\begin{tabular}{|c|c|c|c|c|c|c|c|c|c|c|c|}
\hline $\begin{array}{l}\text { No. } \\
\text { Benda } \\
\text { Uji }\end{array}$ & $\begin{array}{l}\text { Perbandingan } \\
\text { campuran } \\
\text { dalam berat }\end{array}$ & $\begin{array}{l}{ }^{\mathrm{n}} \text { Berat } \\
(\mathrm{kg})\end{array}$ & $\begin{array}{l}\text { Diameter } \\
(\mathrm{cm})\end{array}$ & $\begin{array}{l}\text { Tinggi } \\
(\mathrm{cm})\end{array}$ & $\begin{array}{l}\text { Luas } \\
\text { Penampang } \\
\left(\mathrm{cm}^{2}\right)\end{array}$ & $\begin{array}{l}\text { Volume } \\
\text { Benda Uji } \\
\left(\mathrm{m}^{3}\right)\end{array}$ & $\begin{array}{l}\text { Berat Jenis } \\
\left(\mathrm{kg} / \mathrm{m}^{3}\right)\end{array}$ & $\begin{array}{l}\text { Umur } \\
\text { (hari) }\end{array}$ & $\begin{array}{l}\text { Beban } \\
\text { Maksimum } \\
(\mathrm{kg})\end{array}$ & $\begin{array}{l}\text { Kuat } \\
\text { Tekan } \\
\left(\mathrm{kg} / \mathrm{cm}^{2}\right)\end{array}$ & $\begin{array}{l}\text { Rata } \\
\text { rata } 7 \\
\text { hari } \\
\left(\mathrm{kg} / \mathrm{cm}^{2}\right)\end{array}$ \\
\hline 1. & Normal & 12,05 & 15 & 30 & 176,625 & 0.0053 & 2357,94 & 7 & 24000 & 135.88 & \multirow{3}{*}{137.77} \\
\hline 2. & & 12,31 & 15 & 30 & 176,625 & 0.0053 & 2323,08 & 7 & 22000 & 124.56 & \\
\hline 3. & & 12,27 & 15 & 30 & 176,625 & 0.0053 & 2315,53 & 7 & 27000 & 152.87 & \\
\hline 4. & $\begin{array}{l}\text { Abu sekam } \\
8 \%\end{array}$ & 12,27 & 15 & 30 & 176,625 & 0.0053 & 2291,00 & 7 & 24000 & 135.88 & \multirow{3}{*}{124.56} \\
\hline 5. & & 12,35 & 15 & 30 & 176,625 & 0.0053 & 2324,97 & 7 & 23000 & 130.22 & \\
\hline 6. & & 12,02 & 15 & 30 & 176,625 & 0.0053 & 2328,74 & 7 & 19000 & 107.57 & \\
\hline 7. & $\begin{array}{l}\text { Abu sekam } \\
10 \%\end{array}$ & 12,4 & 15 & 30 & 176,625 & 0.0053 & 2340,06 & 7 & 22000 & 124.56 & \multirow{3}{*}{117.01} \\
\hline 8. & & 12,29 & 15 & 30 & 176,625 & 0.0053 & 2319,31 & 7 & 22000 & 124.56 & \\
\hline 9. & & 12,26 & 15 & 30 & 176,625 & 0.0053 & 2313,64 & 7 & 18000 & 101.91 & \\
\hline 10. & $\begin{array}{l}\text { Abu sekam } \\
12 \%\end{array}$ & 12,14 & 15 & 30 & 176,625 & 0.0053 & 2291,00 & 7 & 19000 & 107.57 & \multirow{3}{*}{107.57} \\
\hline 11. & & 12,32 & 15 & 30 & 176,625 & 0.0053 & 2324,97 & 7 & 19000 & 107.57 & \\
\hline 12. & & 12,34 & 15 & 30 & 176,625 & 0.0053 & 2328,74 & 7 & 19000 & 107.57 & \\
\hline
\end{tabular}

Sumber: Hasil Penelitian, 2017 
Berdasarkan tabel di atas diperoleh hasil bahwa terjadi penurunan kekuatan pada setiap penambahan kadar abu sekam padi. Sehingga didapat nilai kuat tekan rata-rata tertinggi adalah pada beton normal yaitu $137.77 \mathrm{~kg} / \mathrm{cm}^{2}$ dan kuat tekan rata-rata terendah terdapat pada penambahan abu sekam padi $12 \%$ yaitu $107.57 \mathrm{~kg} / \mathrm{cm}^{2}$.

Pada tabel 6 diperoleh nilai kuat tekan beton dari seluruh sample beton normal hingga beton dengan campuran abu sekam $12 \%$. Dari hasil tersebut kemudian dikorelasikan ke umur 14 dan 28 hari untuk mengetahui nilai kuat tekannya. Adapun faktor korelasi terdapat pada tabel di bawah :

Tabel 7 Faktor Korelasi Umur Beton

\begin{tabular}{llll}
\hline 3 hari & 7 hari & 14 hari & 28 hari \\
\hline 0,4 & 0,65 & 0,88 & 1
\end{tabular}

Sumber : PBI 1971

Berikut contoh perhitungan kuat tekan 7 hari dikorelasikan menjadi kuat tekan 28 hari pada jenis beton normal :

Faktor korelasi 7 hari $=$ nilai kuat tekan 7 hari $/$ nilai kuat tekan 28 hari

$$
0,65=137,77 \text { / nilai kuat tekan } 28 \text { hari }
$$

nilai kuat tekan 28 hari $=137,77 / 0,65$

nilai kuat tekan 28 hari $=211,915 \mathrm{~kg} / \mathrm{cm}^{2}$

Perhitungan kuat tekan 14 hari pada beton normal :

Faktor korelasi 14 hari = nilai kuat tekan 14 hari / nilai kuat tekan 28 hari

$0,88=$ nilai kuat tekan 14 hari $/ 211,915$

nilai kuat tekan 14 hari $=211,915 \times 0,88$

nilai kuat tekan 14 hari $=186,517 \mathrm{~kg} / \mathrm{cm}^{2}$

Untuk hasil korelasi selengkapnya bisa dilihat pada tabel di bawah :

Tabel 8. Nilai Kuat Tekan Silinder Setelah Dikorelasi $\left(\mathrm{Kg} / \mathrm{cm}^{2}\right)$

\begin{tabular}{|c|c|c|c|c|}
\hline $\begin{array}{l}\text { Jenis } \\
\text { beton }\end{array}$ & $\begin{array}{c}\text { Kuat } \\
\text { tekan } \\
\text { umur } 7 \\
\text { hari } \\
\left(\mathrm{kg} / \mathrm{cm}^{2}\right)\end{array}$ & $\begin{array}{c}\text { Rata } \\
\text { rata } \\
\text { kuat } \\
\text { tekan } 7 \\
\text { hari } \\
\left(\mathrm{kg} / \mathrm{cm}^{2}\right)\end{array}$ & $\begin{array}{c}\text { Kuat tekan } \\
\text { umur14 } \\
\text { hari } \\
(\mathrm{kg} / \mathrm{cm} 2)\end{array}$ & $\begin{array}{c}\text { Rata } \\
\text { rata } \\
\text { kuat } \\
\text { tekan14 } \\
\text { hari } \\
(\mathrm{kg} / \mathrm{cm} 2 \\
\end{array}$ \\
\hline \multirow{3}{*}{ Normal } & 135,88 & \multirow{3}{*}{147,20} & 183,962 & \multirow{3}{*}{99,29} \\
\hline & 158,53 & & 214,622 & \\
\hline & 147,20 & & 199,292 & \\
\hline \multirow{3}{*}{$\begin{array}{c}\text { abu } \\
\text { sekam } \\
5 \%\end{array}$} & 118,90 & \multirow{3}{*}{122,67} & 160,967 & \multirow{3}{*}{66,07} \\
\hline & 118,90 & & 160,967 & \\
\hline & 130,22 & & 176,297 & \\
\hline \multirow{3}{*}{$\begin{array}{c}\text { abu } \\
\text { sekam } \\
10 \%\end{array}$} & 107,57 & \multirow{3}{*}{111,35} & 145,637 & \multirow{3}{*}{50,74} \\
\hline & 113,23 & & 153,302 & \\
\hline & 113,23 & & 153,302 & \\
\hline abu & 107,57 & \multirow{3}{*}{100,02} & 145,637 & \multirow{3}{*}{35,41} \\
\hline sekam & 101,91 & & 137,972 & \\
\hline $12 \%$ & 90,59 & & 122,641 & \\
\hline
\end{tabular}

\begin{tabular}{|c|c|c|}
\hline Jenis beton & $\begin{array}{c}\text { kuat tekan } \\
28 \text { hari } \\
(\mathrm{kg} / \mathrm{cm} 2)\end{array}$ & $\begin{array}{c}\text { Rata rata kuat } \\
\text { tekan } 28 \text { hari } \\
(\mathrm{kg} / \mathrm{cm} 2)\end{array}$ \\
\hline \multirow{3}{*}{ Normal } & 209,048 & \multirow{3}{*}{211,915} \\
\hline & 191,627 & \\
\hline & 235,179 & \\
\hline \multirow{3}{*}{$\begin{array}{c}\text { abu sekam } \\
8 \%\end{array}$} & 209,048 & \multirow{3}{*}{191,627} \\
\hline & 200,338 & \\
\hline & 165,496 & \\
\hline \multirow{3}{*}{$\begin{array}{c}\text { abu sekam } \\
10 \%\end{array}$} & 191,627 & \multirow{3}{*}{180,013} \\
\hline & 191,627 & \\
\hline & 156,786 & \\
\hline \multirow{3}{*}{$\begin{array}{c}\text { abu sekam } \\
12 \%\end{array}$} & 165,496 & \multirow{3}{*}{165,496} \\
\hline & 165,496 & \\
\hline & 165,496 & \\
\hline
\end{tabular}

Sumber : Hasil Penelitian, 2017

Berdasarkan tabel di atas terjadi penurunan rata-rata nilai kuat tekan setiap penambahan prosentase abu sekam padi

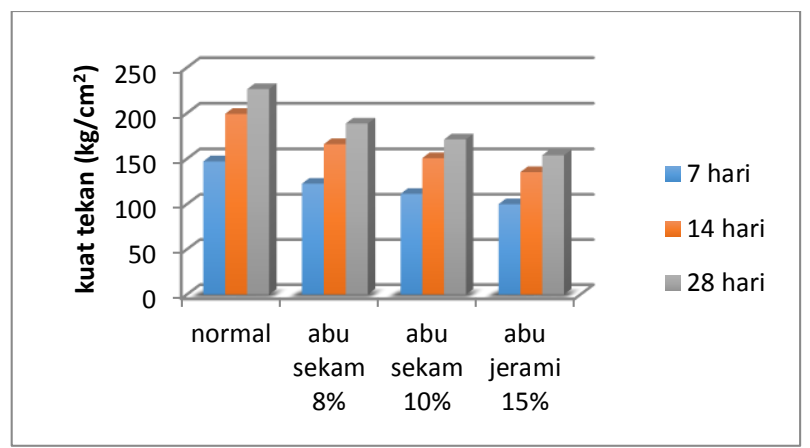

Gambar 2. Grafik pengaruh Persentase Abu sekam Padi $\left(\mathrm{Kg} / \mathrm{cm}^{2}\right)$

Setelah diperoleh data kuat tekan pada umur 14 hari dan 28 hari kemudian dikonversikan menjadi satuan Mpa. Adapun perhitungannya sebagai berikut :

Kuat tekan 7 hari $(\mathrm{Mpa})=($ nilai kuat tekan 7 hari $\mathrm{x} 0,83) \mathrm{x}(9,81 / 100)$

$$
\begin{aligned}
= & (137,77 \times 0,83) \times \\
& (9,81 / 100) \\
= & 11,218 \mathrm{Mpa}
\end{aligned}
$$

Keterangan :

$$
\begin{aligned}
0,83= & \text { nilai konversi benda uji } \\
& \text { berbentuk kubus } 15 \mathrm{~cm} \times 15 \mathrm{~cm} \\
& \times 15 \mathrm{~cm} \text { ke benda uji berbentik } \\
& \text { silinder ber diameter } 15 \mathrm{~cm} \\
& \text { dengan tinggi } 30 \mathrm{~cm} \\
9,81 / 100= & \text { nilai konversi dari satuan } \\
& \mathrm{kg} / \mathrm{cm}^{2} \text { ke satuan Mpa }
\end{aligned}
$$


Tabel 9. Kuat Tekan Silinder Setelah Konversi (Mpa)

\begin{tabular}{|c|c|c|c|c|c|c|}
\hline $\begin{array}{l}\text { Jenis } \\
\text { beton }\end{array}$ & $\begin{array}{c}\text { kuat } \\
\text { tekan } 7 \\
\text { hari } \\
\text { (Mpa) }\end{array}$ & $\begin{array}{c}\text { Rata } \\
\text { rata } \\
\text { kuat } \\
\text { tekan } 7 \\
\text { hari } \\
\text { (Mpa) }\end{array}$ & $\begin{array}{c}\text { kuat } \\
\text { tekan } 14 \\
\text { hari } \\
\text { (Mpa) }\end{array}$ & $\begin{array}{c}\text { Rata } \\
\text { rata } \\
\text { kuat } \\
\text { tekan } \\
\text { 14 hari } \\
\text { (Mpa) }\end{array}$ & $\begin{array}{c}\text { kuat } \\
\text { tekan } 28 \\
\text { hari } \\
\text { (Mpa) }\end{array}$ & $\begin{array}{c}\text { Rata } \\
\text { rata } \\
\text { kuat } \\
\text { tekan } \\
28 \text { hari } \\
\text { (Mpa) }\end{array}$ \\
\hline \multirow{3}{*}{ Normal } & 11,064 & \multirow{3}{*}{11,218} & 14,979 & \multirow{3}{*}{15,187} & 17,021 & \multirow{3}{*}{17,258} \\
\hline & 10,142 & & 13,731 & & 15,603 & \\
\hline & 12,447 & & 16,851 & & 19,149 & \\
\hline \multirow{3}{*}{$\begin{array}{c}\text { abu } \\
\text { sekam } \\
8 \%\end{array}$} & 11,064 & \multirow{3}{*}{10,142} & 14,979 & \multirow{3}{*}{13,731} & 17,021 & \multirow{3}{*}{15,603} \\
\hline & 10,603 & & 14,355 & & 16,312 & \\
\hline & 8,759 & & 11,858 & & 13,475 & \\
\hline \multirow{3}{*}{$\begin{array}{c}\text { abu } \\
\text { sekam } \\
10 \%\end{array}$} & 10,142 & \multirow{3}{*}{9,527} & 13,731 & \multirow{3}{*}{12,898} & 15,063 & \multirow{3}{*}{14,657} \\
\hline & 10,142 & & 13,731 & & 15,063 & \\
\hline & 8,298 & & 11,234 & & 12,766 & \\
\hline \multirow{3}{*}{$\begin{array}{c}\text { abu } \\
\text { sekam } \\
12 \%\end{array}$} & 8,759 & \multirow{3}{*}{8,759} & 11,858 & \multirow{3}{*}{11,858} & 13,475 & \multirow{3}{*}{13,475} \\
\hline & 8,759 & & 11,858 & & 13,475 & \\
\hline & 8,759 & & 11,858 & & 13,475 & \\
\hline
\end{tabular}

Berdasarkan tabel di atas terjadi penurunan rata-rata nilai kuat tekan setiap penambahan prosentase abu sekam padi

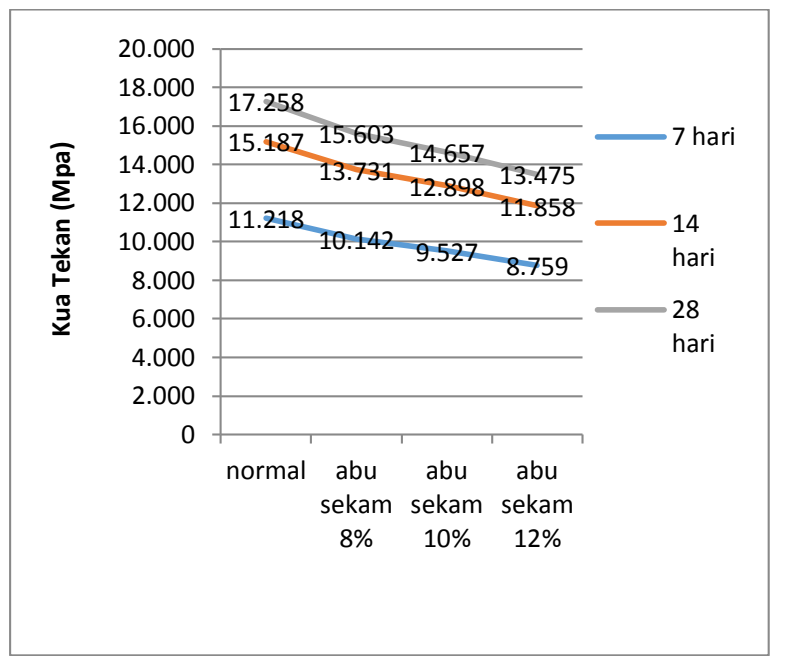

Gambar 3. Grafik pengaruh Persentase Abu sekam Padi Terhadap Nilai Kuat Tekan Beton (Mpa)

\section{KESIMPULAN}

Dari data yang diperoleh dan dari analisa data yang telah dilakukan maka dapat diambil kesimpulan sebagai berikut :

Proses pembuatan bendauji dimulai dengan membersihkan concrete mixer dari kotoran dengan cara membilas dengan air bersih. Hal ini dilakukan untuk menjaga mutu beton yang akan di buat agar tidak berkurang. Masukkan agregat kasar (kerikil) kedalam concrete mixer kemudian agregat halus (pasir). Setelah agregat halus dan agregat kasar tercampur rata masukkan semen Portland dan abu sekam padi, tunggu hingga tercampur rata. Masukkan air hingga semua material tersebut tercampur rata kemudian masukkan beton segar tersebut kedalam cetakan silinder.

Berdasarkan hasil dari data pada bab sebelumnya, penggunaan abu sekam padi pada campuran beton dengan variasi penambahan $0 \%, 8 \%, 10 \%$, dan $12 \%$ dari berat semen berdampak terhadap penurunan nilai kuat tekan beton. Nilai kuat tekan yang diperoleh pada umur 28 hari yaitu 11.218 Mpa, 10.142 Mpa,9.527 Mpa, dan 8.759 Mpa. Maka penelitian ini berbanding terbalik dengan penelitian terdahulu yang menyatakan bahwa semakin banyak prosentase penambahan abu sekam padi maka semakin kuat pula kuat tekan beton yang di hasilkan.

\section{SARAN}

Adapun saran yang diperoleh sebagai berikut :

1. Aplikasi dari penelitian beton dengan tambahan abu sekam padi ini dapat digunakan pada bagian bangunan non struktural.

2. Diharapkan agar campuran antara semen dan abu sekam padi serta material - material pembentuk lainnya benar - benar homogen agar menghasilkan beton yang baik.

\section{REFERENSI}

Hidayat. 2011. Pengaruh Penambahan Abu Sekam Padi Terhadap Kuat Tekan Beton $K$-225 Universitas Pasir Pangairan

Sri Raharja, Sholihin As'ad, dan Sunarmasto. 2011. Pengaruh Penggunaan Abu Sekam Padi Sebagai Bahan Pengganti Sebagian Semen Terhadap Kuat Tekan Dan Modulus Elastisitas Beton Kinerja Tinggi. Universitas Sebelas Maret : Surakarta

Lakum, K. 2011. Pemanfaatan Abu Sekam Padi Sebagai Campuran Untuk Pengganti 
J u r n a l T e k n i k A

sebagian Semen Dalam Pembuatan Beton. Universitas Sumatra Utara.

Malasyi, Syibral, Fasdarsyah dan Wesli. 2014. Analisis Pengaruh Penggunaan Abu Jerami Terhadap Kuat Tekan Beton. Universitas Malikussaleh : Aceh.

Muharrisa, Raisa dan Rahmi Karolina. 2009. Pengaruh Penambahan Serat Jerami Padi sebagai Peredam Suara dan Pengaruhnya Terhadap Sifat Mekanik Beton. Universitas Sumatera Utara : Medan.

Nawi, Edward G. 1998. Beton Bertulang Suatu Pendekatan Dasar. PT Refika Aditama: Bandung.

Nofa, Rini Sri. 2012. Ekstrasi Silika Dari Sekam Dan Jerami Padi Sebagai Penyerap Ion Logam Cd (II). Universitas Negeri Malang : Malang.

Wijanarko, Wisnu. 2009.Analisis Bahan Jerami Padi Dalam Bentuk BlockAtau Kotak
Sebagai Bahan Pengisi Batako. Universitas Sebelas Maret : Surakarta.

Referensi dari website :

Ahadi. 2011.Agregat Halus Kasar. http://www.ilmusipil.com/agregat-haluskasar. Diakses tanggal 3 maret 2017. http://eproduk.litbang.pertanian.go.id/product. php?id_product $=130$ diakses tanggal 22 juli 2017.

http://www.lamongankab.go.id/portal/58uncategorized/1880-karanglangit.html diakses tanggal 22 juli 2017.

http://kbbi.web.id. Diakses tanggal 13 januari 2017.

Kirana, Febrian Sasi. 2011. Portland Cement. http://febriansasi.blogspot.co.id/2011/12/portla nd-cement.html. Diakses tanggal 13 januari 2017. 
Halaman ini sengaja dikosongkan 